\title{
THIENEMANNIA SPIESI SP. NOV., A CRENOPHILOUS SPECIES FROM THE SCHAPBACH QUELLE, BAVARIA, GERMANY (DIPTERA: CHIRONOMIDAE: ORTHOCLADIINAE)
}

\author{
JOEL MOUBAYED-BREIL ${ }^{1, *}$ and PATRICK ASHE ${ }^{2}$ \\ ${ }^{1}$ Biodiversity, Marine and Freshwater, 10 rue des Fenouils, F-34070 Montpellier, France \\ 233 Shelton Drive, Terenure, Dublin 12, Ireland \\ * Corresponding author: joelmb34@free.fr
}

\section{ABSTRACT}

A description of the male and female imago and pupal exuviae of Thienemannia spiesi sp. nov. is provided based on material collected in the Schapbach Quelle (spring), Bavaria, Germany. This description increases the total number of species known worldwide in the genus to eleven. The new species, T. spiesi, can be distinguished from other related species (except T. libanica Laville and Moubayed 1985) by the following combination of characters: chaetotaxy of the wing membrane, inferior volsella nose-shaped and not sinuous, gonostylus bearing a crista dorsalis, spines present on tergite VII of the pupal exuviae. Comments on its ecology and taxonomic position are provided.

Keywords: Diptera, Chironomidae, Thienemannia spiesi sp. nov., ecology, distribution

doi: $10.14712 / 23361964.2016 .10$

\section{Introduction}

The present description is based on adults, pharate adults and pupal exuviae belonging to two species of the genus Thienemannia Kieffer, 1909. Specimens examined belong to T. libanica Laville and Moubayed, 1985 (from Lebanon) and T. spiesi sp. nov. (from Germany) and both are closely related and considered to be sister species based on both adults and pupal exuviae. In Moubayed-Breil and Ashe (2013) T. spiesi sp. nov. is listed under the name Thienemannia sp. 1. The pupal exuviae of the new species resembles those of two recently described species: T. corsicana Moubayed-Breil 2013 (Moubayed-Breil 2013) and T. valespira Moubayed-Breil and Ashe 2013 (Moubayed-Breil and Ashe 2013). Records of T. libanica listed in Schacht (2010) and Sæther and Spies (2013) from Germany are referable to T. spiesi sp. nov. and those from elsewhere in Europe (Denmark, France, Luxembourg, Portugal, Spain) are probably misidentifications of either T. spiesi sp. nov. or some other related species. With the description here of T. spiesi sp. nov., there are now eleven valid species of Thienemannia Kieffer, 1909 known worldwide. The genus Thienemannia is known from the western Palaearctic (Europe and the Near East), the Nearctic and the Oriental Region (Ashe and O'Connor 2012).

The description of the male and female adult and pupal exuviae of T. spiesi sp. nov. is given based on material collected in Schapbach Quelle (30.VII.1999, altitude $1,170 \mathrm{~m}$, Bavaria, Germany) which had previously been misidentified as $T$. libanica. Terminology and measurements follow Sæther $(1980,1985)$ and Langton and Pinder (2007) for the male adult and Sæther (1980) and Langton (1991) for pupal exuviae. Comments on the taxonomic position and ecology of the new species are given.

\section{Thienemannia spiesi sp. nov.}

Thienemannia libanica: in Schacht (2010), misidentified.

Thienemannia sp. 1: in Moubayed-Breil and Ashe 2013 (Figs. 19-20, 32)

\section{Material Examined}

Holotype: GERMANY: Bavaria, Nationalpark Berchtesgaden (BGL), Schapbach Quelle (spring), altitude 1,170 m, 30.VII.1999, 1 pharate adult male.

Paratypes: 4 pharate adults ( 2 males and 2 females) including 4 associated pupal exuviae ( 2 males and $2 \mathrm{fe}$ males); same locality and date as holotype.

Holotype and paratypes are deposited in the collection of the Zoologische Staatssammlung (ZSM), Munich, Germany. Type material was mounted on five slides in polyvinyl lactophenol mountant.

Etymology: The new species is named spiesi after our colleague Martin Spies from the Zoologische Staatssammlung (ZSM), Munich, Germany, in appreciation for his assistance and the loan of material.

\section{Description \\ Male imago (Figs. 1a, 1e, 1f, 1h; 2a-d)}

( $\mathrm{n}=3$ pharate adult males)

A relatively small sized species (among the smallest in Thienemannia). Total length $1.35-1.45 \mathrm{~mm}$. Wing length $1.15-1.20 \mathrm{~mm}$. General colouration: contrasting dark brown to brown, especially on the thorax. Head and antenna brown including antennal and wing sheath, halteres brown. Thorax dark brown to brown, with brown mesonotal strips. Wing membrane transparent, without 
shading. Legs dark brown to brown; tarsi of PI, PII and PIII blackish apically.

Head: Eyes hairy between ommatidia, hairs present along proximal half of inner eye margin (Fig. 1a). Temporal setae $2-3$, including 2-3 inner verticals, 0 outer verticals, postorbitals absent. Clypeus with 14-16 setae. Palp 5-segmented, length $(\mu \mathrm{m})$ of segments: 14-16, 19$21,34-35,51-55,73-75$; sensilla clavata absent on third segment; last segment bearing 3 apical setae. Antenna 330-340 $\mu \mathrm{m}$ long, 10-segmented (Fig. 1f), segments 1 to 3 globulous (respectively 32, 27, $29 \mu \mathrm{m}$ long); segments 4 to 8 subequal (each 29-30 $\mu \mathrm{m}$ long); segment 9, $25 \mu \mathrm{m}$ long; ultimate flagellomere (Fig. 1e) 80-87 $\mu \mathrm{m}$ long, slightly clubbed, bearing 1 long apical seta (30 $\mu \mathrm{m}$ long), sensilla chaetica present on distal half. AR 0.32-0.35.

Thorax: Antepronotum with 4 lateral setae, median setae absent. Dorsocentrals 21-22; acrostichals 1618 uni- to biserial, including 9-10 placed in front near the antepronotum, 7-8 distally; prealars 4-5. Scutellum with 4 setae in a single row. Preepisternum bare.

Wing (Fig. 1h, distal half): Brachiolum with 2 setae. Venation and distribution of setae on veins, membrane and cells: $\mathrm{R}, 7-8 ; \mathrm{R}_{1}, 3-5 ; \mathrm{R}_{2+3}, 9-11 ; \mathrm{An}, 0 ; \mathrm{Cu}_{1}, 0 ; \mathrm{r}_{4+5}$, $4 ; \mathrm{m}_{1+2}, 3 ; \mathrm{m}_{3+4}, 0 ; \mathrm{cu}, 0$; an, 0 . Anal lobe weak. Squama with 1-2 setae. The distribution pattern of setae on wing cells is regarded as an important distinguishing feature to separate T. spiesi from other related species, especially T. libanica.

Legs: Spur of front tibia $23 \mu \mathrm{m}$ long, spurs of middle tibia 35 and $23 \mu \mathrm{m}$ long, spurs of hind tibia 13 and $15 \mu \mathrm{m}$ long; hind comb with 12 setae. Fourth tarsus $\left(\operatorname{ta}_{4}\right)$ on PI distinctly bilobed apically, on PII and PIII weakly bilobed. Length $(\mu \mathrm{m})$ and proportions of legs:

$\begin{array}{llllllllllll} & \mathrm{fe} & \mathrm{ti} & \mathrm{ta}_{1} & \mathrm{ta}_{2} & \mathrm{ta}_{3} & \mathrm{ta}_{4} & \mathrm{ta}_{5} & \mathrm{LR} & \mathrm{BV} & \mathrm{SV} & \mathrm{BR} \\ \mathrm{PI} & 275 & 310 & 137 & 91 & 66 & 43 & 49 & 0.44 & 2.90 & 4.27 & 1.8 \\ \mathrm{PII} & 325 & 316 & 161 & 83 & 75 & 46 & 48 & 0.51 & 3.10 & 3.98 & 1.0 \\ \text { PIII } & 331 & 322 & 162 & 86 & 71 & 47 & 46 & 0.50 & 3.26 & 4.03 & 1.1\end{array}$

Hypopygium in dorsal and ventral view (Fig. 2a): Anal point 17-18 $\mu \mathrm{m}$ long; tergite IX 61-66 $\mu \mathrm{m}$ wide, broad with a nearly straight basal margin, bearing 9-10 setae (4 to 5 on each side of the anal point). Laterosternite IX with 2 setae. Transversal sternapodeme and phallapodeme as in Fig. 2a. Virga (Fig. 2b) semicircular and faint. Gonocoxite 112-115 $\mu \mathrm{m}$ long, maximum width $55 \mu \mathrm{m}$; inferior volsella (Figs. 2a, 2c) 7-8 $\mu \mathrm{m}$ long, 6-7 $\mu \mathrm{m}$ wide, nose-shaped, outer ventral margin straight, not swollen basally. Gonostylus (Fig. 2a) 57-63 $\mu \mathrm{m}$ long, triangular with pointed apex, bearing 5 or 6 stout orally directed setae; crista dorsalis swollen proximally; megaseta $8-10 \mu \mathrm{m}$ long, slightly curved apically.

Female imago (Figs. 3a-e)

( $\mathrm{n}=2$, pharate adult females)

Colouration: as in the male adult except for the legs, which are brownish to dark brown including femora,
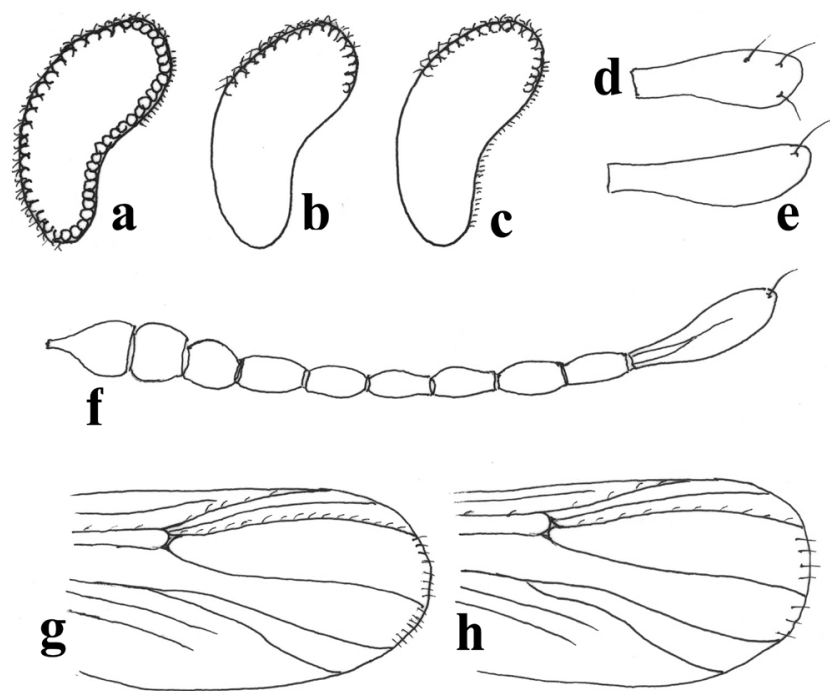

Fig. 1 Thienemannia spp. Hairs on inner margin of eyes: T. spiesi sp. nov. (a); T. libanica (b), Lebanon; T. corsicana (c), Corsica. Last flagellomere of antenna of: libanica (d); spiesi (e). Antenna of T. spiesi (f). Distal half of wing (g-h) of: libanica $(\mathrm{g})$; spiesi ( $\mathrm{h})$.

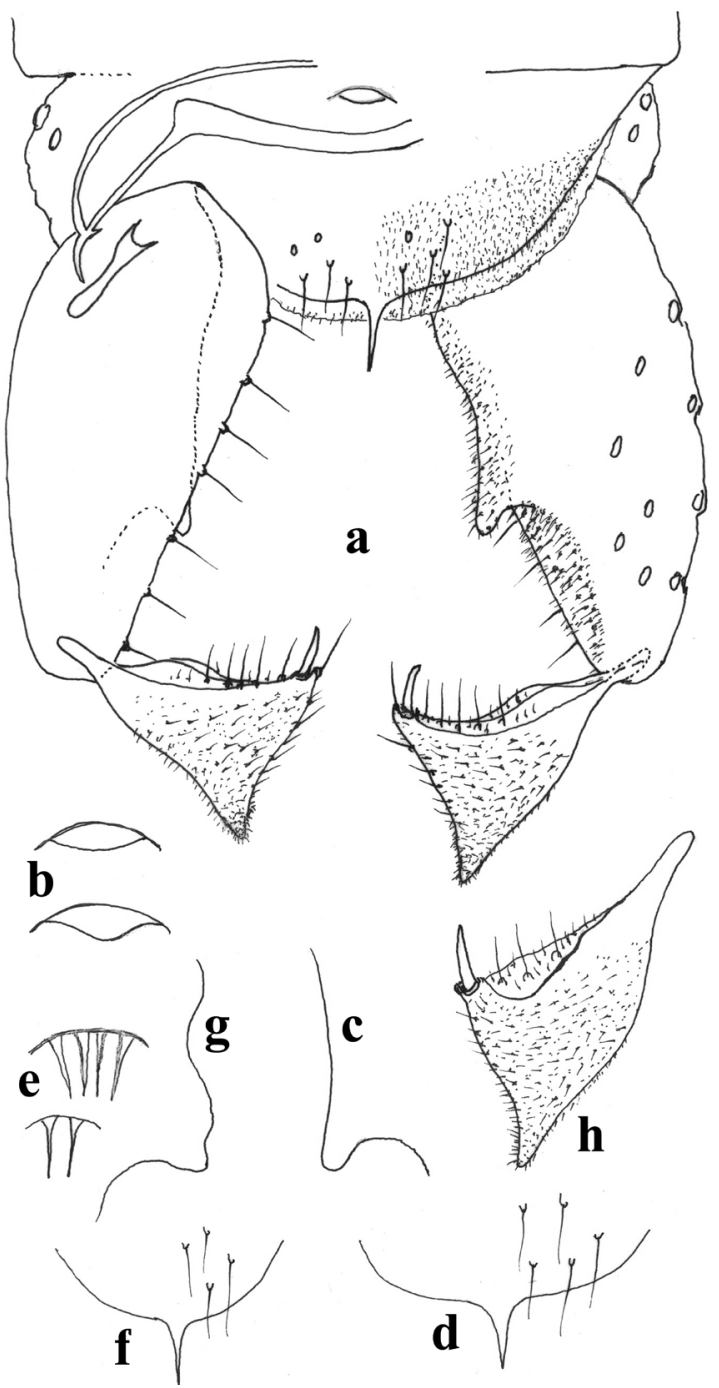

Fig. 2 Male imago of Thienemannia spp. T. spiesi sp. nov. (a-d): hypopygium, ventral, left and dorsal, right (a); Virga (b); inferior volsella (c); tergite IX and anal point (d). T. libanica: two aspects of virga (e); tergite IX and anal point (f); inferior volsella $(\mathrm{g})$; gonostylus (h). 
tibia and tarsi. Total length 1.50-1.60 mm. Wing length $1.20-1.30 \mathrm{~mm}$. Antenna length $0.165-0.175 \mathrm{~mm}$.

Head: Eyes hairy, hairs present on median part of inner eye margin; temporal setae 4 , including 1 inner and 3 outer verticals, postorbitals absent. Clypeus with 8 setae. Antenna (Fig. 3a) 5-segmented; length ( $\mu \mathrm{m})$ of segments: 31, 33, 26, 30, 55; ultimate flagellomere moderately clubbed, bearing 1 apical seta; AR 0.18.

Thorax: Antepronotum with 2 lateral setae, median setae absent; acrostichals 17 , relatively long, starting close to antepronotum; dorsocentrals 7; prealars 6. Scutellum with 6 setae in a single row. Preepisternum bare.

Wing: Brachiolum with 2 setae. Distribution of setae on veins, membrane and cells: $\mathrm{R}, 14 ; \mathrm{R}_{1}, 26 ; \mathrm{R}_{2+3}, 5 ; \mathrm{R}_{4+5}$ 13; $\mathrm{Cu}_{1}, 4 ; \mathrm{An}, 9 ; \mathrm{r}_{2+3}, 0 ; \mathrm{r}_{4+5}, 23 ; \mathrm{m}_{1+2}, 4 ; \mathrm{m}_{3+4}, 3 ; \mathrm{cu}, 0$; an, 0 . Anal lobe weak. Squama with 2 setae.

Genitalia in dorsal and ventral view (Figs. 3b-e): Notum with distinct rami. Gonapophysis VIII (Figs. 3b-c); dorsomesal lobe (Fig. 3b) straight, ventrolateral lobe (Fig. 3b) large; apodeme lobe (Fig. 3c) sickle-like; gonocoxite (Fig. 3d) slightly elongated, bearing 5-6 setae; tergite IX (Fig. 3e) nearly semi-circular with 9 setae; sternite VIII with 8 setae. Seminal capsules $75 \mu \mathrm{m}$ long, $51 \mu \mathrm{m}$ wide, pear-shaped. Spermathecal ducts with loops and separate openings.

Pupal exuviae (Figs. $4 \mathrm{a}-\mathrm{d}$ )

$(\mathrm{n}=4)$

Colouration: yellowish to yellow brown in general; thorax, yellowish brown with faint brown granulations near thoracic suture and dorsocentral area; antennal and wing sheaths with faint brownish shading; abdomen including anal segment brownish; with brownish apophyses; anterior area of tergites III-VIII brownish. Total length $1.40-1.50 \mathrm{~mm}$.

Cephalothorax (Figs. 4a-b): Frontal apotome (Fig. 4a) slightly rugulose, frontal setae 13-15 $\mu \mathrm{m}$ long. Postorbit-

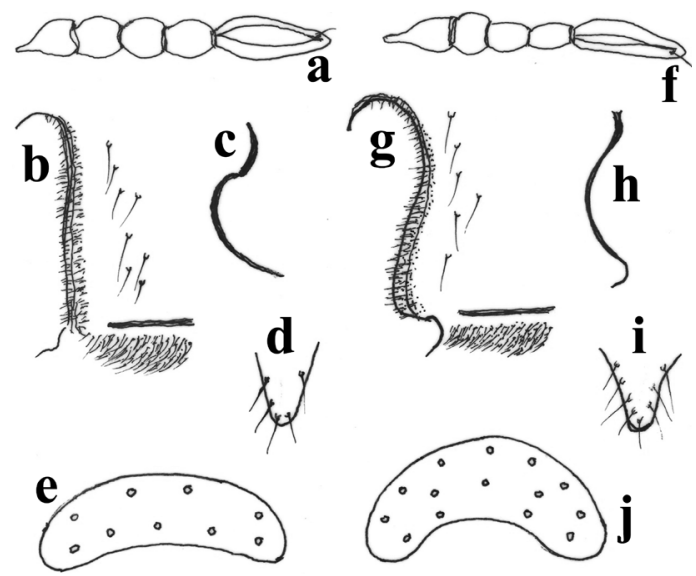

Fig. 3 Female imago of Thienemannia spp. T. spiesi sp. nov. (a-e): antenna (a), gonapophysis VIII, dorsomesal, ventrolateral and apodeme lobes (b); apodeme lobe (c); gonocoxite (d); tergite IX in dorsal view (e). T. libanica $(f-j)$ : antenna $(f)$; gonapophysis VIII, dorsomesal, ventrolateral and apodeme lobes (g); apodeme lobe (h); gonocoxite, (i); tergite IX (j). als and vertical minute and weak. Thoracic horn absent. Median antepronotals 23 and $33 \mu \mathrm{m}$ long; precorneal setae 28, 33 and $21 \mu \mathrm{m}$ long. Dorsocentrals 9-12 $\mu \mathrm{m}$ long, inserted as in Fig. 4b; Dc2-Dc4 inserted close together; distance between Dc1 and Dc2, $61 \mu \mathrm{m} ; \mathrm{Dc} 2, \mathrm{Dc} 3$ and Dc4 equidistant, each separated by about $9 \mu \mathrm{m}$.

Abdomen (Figs. 4c-d): Armament and distribution pattern of shagreen, patch of spines and spinules, chaetotaxy and lateral setation of segments as in Fig. 4c. Tergite I bare. Posterior transverse tooth row present on tergites III-VIII; tooth row on tergite II-VIII consists of 21-27 teeth in one continuous row; in general, teeth are mostly rounded at apices. Tergites II-III without anteromedian patch of shagreen or circular rows of spinulae. Transverse anterior shagreen present on tergites III-VIII consisting of spinules (III-VI), which increase medially to larger sized spines on tergites VII and VIII (8-10 spines on anterior part of tergite VII; 21-23 anteriorly and medially on tergite VIII). Anterior median circular patch of strong spinules present only on tergites VIII-IX; patch of strong spines and rows of spinules are connected on tergites VII and VIII. Sternites I-VIII bare. Conjunctives of intersegments I-VII with rows of anteriorly directed, long pointed spinules (Figs. $4 \mathrm{c}-\mathrm{d}$ ). Pedes spurii A and $\mathrm{B}$ absent. Lateral abdominal setae weak and hair-like,

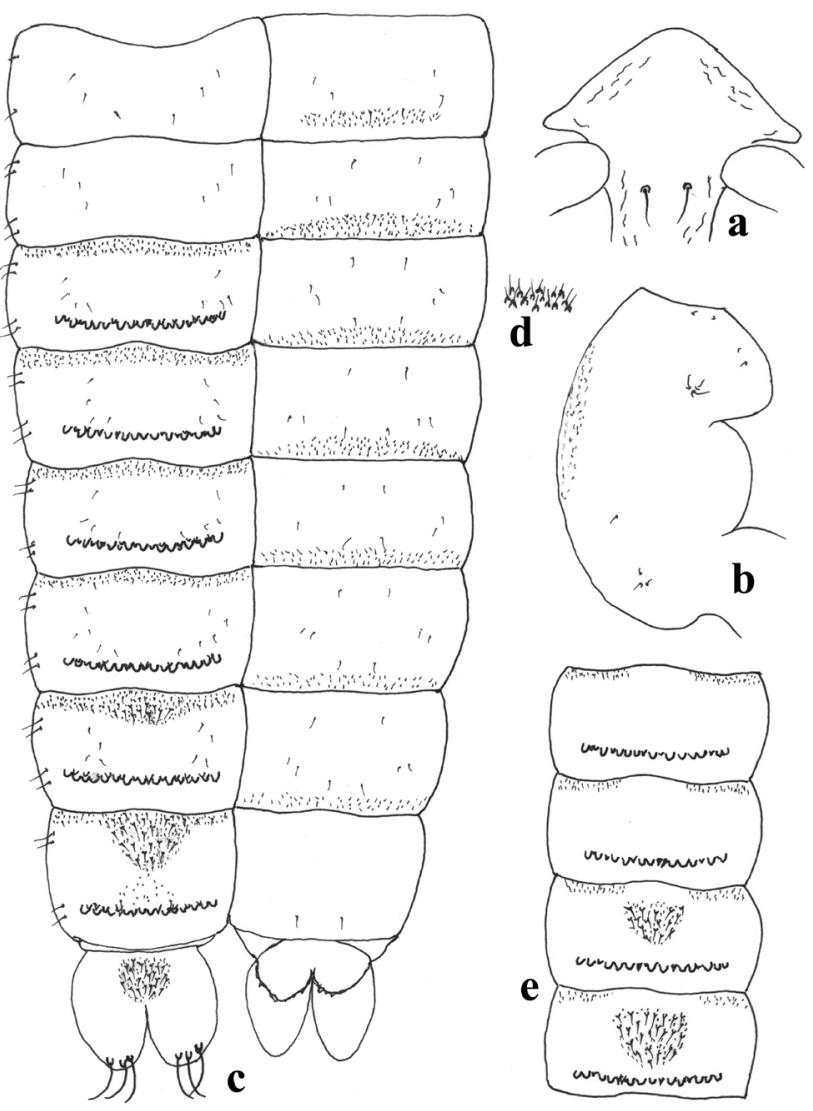

Fig. 4 Thienemannia spp. Male pupal exuviae of $T$. spiesi sp. nov. (a-d): frontal apotome (a); cephalothorax (b); abdominal segments I-IX with armament of tergites (left) and sternites (right) (c); details of transversal rows of orally directed long pointed spinules on conjunctives of intersegments II-VII (d). T. libanica: armament of tergites V-VIII (e). 
consisting of reduced minute setae: tergite I with 2 setae, tergites II-VIII each with 4 setae. Apophyses brownish and relatively straight. Anal lobe $123-125 \mu \mathrm{m}$ long, apical margin rounded; macrosetae 65-67 $\mu \mathrm{m}$ long, stout and slightly curved distally as in all Thienemannia pupal exuviae (Sæther 1985). Genital sac 63-67 $\mu \mathrm{m}$ long, rounded apically.

\section{Taxonomic Position}

The most important diagnostic features used to distinguish species in the genus Thienemannia genus are: chaetotaxy of the wing including the wing membrane; shape and form of the hypopygium including that of the virga, tergite IX, inferior volsella and gonostylus.

In the male adult, distinguishing characters between T. spiesi and T. libanica include: presence of hairs on proximal area of inner lateral margin of eye in T. spiesi (Fig. 1a), bare in T. libanica (Fig. 1b); last flagellomere elongated in T. spiesi (Fig. 1e), distinctly clubbed in T. libanica (Fig. 1d); chaetotaxy of cells $\mathrm{r}_{4+5}$ and $\mathrm{m}_{1+2}$ are different in the two species (Fig. 1h, T. spiesi; Fig.1g, T. libanica); virga not toothed in T. spiesi (Figs. 2a-b), bearing 2-4 spines in T. libanica (Fig. 2e); tergite IX wide, with a more or less straight basal margin in T. spiesi (Fig. 2d), rounded and tapered in T. libanica (Fig. 2f); inferior volsella nose-shaped in T. spiesi (Fig. 2c), swollen in T. libanica (Fig. 2g); outer margin of inferior volsella straight in T. spiesi (Fig. 2c), sinuous in T. libanica (Fig. 2g); crista dorsalis distinctly present on proximal part in T. spiesi (Fig. 2a), absent in T. libanica (Fig. 2h). In addition, the broad and more or less straight basal margin of tergite IX keys T. spiesi near both T. gracilis Kieffer, 1909 and T. valespira. (Moubayed-Breil and Ashe 2013, Figs. 1415). However, a narrowed and tapered basal margin of tergite IX is found in both T. libanica (Fig. 2f) and T. corsicana (Moubayed-Breil 2013, Fig. 7).

In the female adult T. spiesi is separated from its sister species T. libanica by the following characters: the distribution of setae on wing veins, membrane and cells is quite similar to that in T. libanica but their number is much lower in T. spiesi; ventrolateral and dorsomesal lobes straight in T. spiesi (Fig. 3b), swollen distally in T. libanica (Fig. 3g); tergite IX semi-circular in T. libanica (Fig. 3j), less convex in T. spiesi (Fig. 3e).

The pupal exuviae of T. spiesi is distinguishable from other related species (especially T. libanica, T. corsicana and T. valespira) by the following characters: suture of pupal thorax bearing faint granulations in T. spiesi (Fig. $4 \mathrm{~b})$, bare in T. libanica, densely granulated in T. corsica$n a$ and T. valespira; anterior-median patch on tergite VII includes spinules and a few spines in T. spiesi (Fig. 4c), while spines are lacking in T. corsicana (Moubayed-Breil 2013, Fig. 12) and in T. libanica (Fig. 4e); transverse anterior rows of shagreen on tergites III-VIII continuous in T. spiesi, T. corsicana and T. valespira while it is interrupted medially in T. libanica (Fig.4e). The median patch of spines on tergite VIII in T. spiesi (Fig.4c) is connected to the anterior row of shagreen while in T. libanica (Fig. 4e) they are disconnected and the anterior row of shagreen is interrupted.

\section{Ecology and Distribution}

Thienemannia spiesi sp. nov. is currently known only from the Nationalpark Berchtesgaden in Bavaria, Germany. This new species is typically crenophilous and confined to helocrenes where shady and fresh habitats are characterized by a siliceous substratum and a low water conductivity value $(\mathrm{Cd}, 10-13 \mu \mathrm{S} / \mathrm{cm})$. Larvae of this new species are typically rheophilic occurring in running water of a spring in Bavaria. Two other orthoclad species, Heterotrissocladius zierli Stur and Wiedenbrug, 2005 and Tavastia alticrista Stur and Wiedenbrug, 2005, have been described from another spring in the same national park in Bavaria (Stur and Wiedenbrug 2005). The general description of the type locality where the associated pharate adult material was collected is detailed in a recent paper by Gerecke et al. (2011). Comparative ecological data given for T. libanica shows that this species, from Chlefa in Lebanon, is a typically rhithrobiontic species inhabiting karstic water with a high water conductivity value (Cd, up to $300 \mu \mathrm{S} / \mathrm{cm}$ ).

Thienemannia spiesi sp. nov. from Germany has been confused with $T$. libanica due to the strong resemblance between their respective pupal exuviae. However, T. libanica is only known with certainty from a single locality in Lebanon: the upper stream of Yammouna-Chlefa (altitude 1,100-1,200 m), which is located in the inner plain of Bekaa (Laville and Moubayed 1985). Despite extensive investigations made throughout Lebanon, T. libanica is still unknown and apparently absent from coastal high mountain streams located in the eastern Mediterranean, including the Levantine Province. Further doubtful and probably misidentified records of T. libanica have been reported, based on pupal material, from some areas located in northern, central and southern Europe (Serra-Tosio and Laville 1991, zone E4; Moubayed et al. 2000, zone 3; Moubayed-Breil 2008, zones 5b and 10; Schacht 2010; Ashe and O'Connor 2012; Fauna Europaea, Sæther and Spies 2013). Therefore, some records of T. libanica from Europe may refer to T. valespira, T. spiesi sp. nov or some other related species. Occurrence of this new rheophilic species in a helocrene in Bavaria (Germany) indicates that it may be more widespread in cold high mountain springs and streams of central and southern Europe and therefore can be expected from such habitats in, for example, Austria, Switzerland, Italy and Spain.

Associated species encountered in the same locality include cold stenothermic and crenophilous elements (considered as typical helocrene species by Thienemann 1954, Lindegaard 1995, Stur and Wiedenbrug 2005, Moubayed-Breil and Ashe 2012) are: Diamesa cinerella (Meigen 1835), D. macronyx (Kieffer 1918), Bryophaenocladius nidorum (Edwards 1929), B. subvernalis (Ed- 
wards 1929), B. vernalis (Goetghebuer 1921), Chaetocladius dissipatus (Edwards 1929), C. laminatus (Brundin 1947), C. suecicus (Kieffer 1916), Heterotrissocladius zierli, Parakiefferiella gracillima (Kieffer 1922), Metriocnemus eurynotus (Holmgren, 1883), Rheocricotopus effusus (Walker 1856), Tavastia alticrista, Tvetenia bavarica (Goetghebuer 1934), Micropsectra mendli (Reiss 1983) and M. sofiae (Stur and Ekrem 2006).

\section{Acknowledgements}

The authors are grateful to Martin Spies, Zoologische Staatssammlung (ZSM), Munich, Germany, for the loan of specimens on which the description of the new species is based.

\section{REFERENCES}

Ashe P, O'Connor JP (2012) A World Catalogue of Chironomidae (Diptera). Part 2. Orthocladiinae. Irish Biogeographical Society \& National Museum of Ireland, Dublin.

Gerecke R, Cantonati M, Spitale D, Stur E, Wiedenbrug S (2011) The challenge of long-term ecological research in springs in northern and southern Alps: indicators groups, habitat diversity, and medium term change. J Limnol 70 (Suppl 1): 168-187.

Langton PH (1991) A key to pupal exuviae of the West Palaearctic Chironomidae. Privately published, Huntingdon, England.

Langton PH, Pinder LCV (2007) Keys to the adult males of Chironomidae of Britain and Ireland. Volume 1 (pp: 1-239) and Volume 2 (pp: 1-68). Freshwater Biological Association, Scientific Publication No. 64.

Laville H, Moubayed Z (1985) Les Chironomidés (Diptera) du Liban. II. Description de l'imago $\sigma^{7}$ et de la nymphe de Thienemannia libanica n.sp. Annals Limnol 21: 77-82.
Lindegaard C (1995) Chironomidae (Diptera) of European cold springs and factors influencing their distribution. In: Ferrington Jr LC (ed) Biodiversity of aquatic insects and other invertebrates in springs. Spec Publ 1. J Kans Entomol Soc 68 (Suppl 2): $108-131$.

Moubayed-Breil J (2008) Non-biting midges from Continental France: new records, faunal and biogeographical outline [Diptera, Chironomidae]. Ephemera 9: 17-32.

Moubayed-Breil J (2013) Description of Thienemannia corsicana sp. n. from the upstream of Golu River in Corsica [Diptera, Chironomidae, Orthocladiinae]. Ephemera 13: 79-86.

Moubayed-Breil J, Ashe P (2012) An updated checklist of the Chironomidae of Corsica with an outline of their altitudinal and geographical distribution [Diptera]. Ephemera 13: 13-39.

Moubayed-Breil J, Ashe P (2013) Thienemannia valespira sp. n., a mountain crenophilous element from the Eastern Pyrenees and the Alps [Diptera, Chironomidae]. Ephemera 14: 13-24.

Sæther OA (1980) Glossary of Chironomid morphology terminology (Diptera, Chironomidae). Ent Scand Suppl 14: 1-51.

Sæther OA (1985) Redefinition and review of Thienemannia Kieffer, 1909 (Diptera: Chironomidae), with the description of $T$. pilinucha sp. n. Aquat Insects 7: 111-131.

Sæther OA, Spies M (2013) Fauna Europaea: Chironomidae. In: Beuk P, Pape T. (eds) Fauna Europaea: Diptera Nematocera. Fauna Europaea version 2.6. Internet database at http://www faunaeur.org.

Schacht W (2010) Katalog der Zweiflügler (Mücken und Fliegen) Bayerns Familienliste - Artenliste - Literaturverzeichnis - Bestimmungsliteratur (Insecta: Diptera). Zoologische Staatssammlung München. Internet database at http://www.zsm .mwn.de/dip/DiptBayKat.pdf.

Serra-Tosio B, Laville H (1991) Liste annotée des Chironomides de France continentale et de Corse. Annals Limnol 27: 37-74.

Stur E, Wiedenbrug S (2005) Two new orthoclad species (Diptera: Chironomidae) from cold water springs of the Nationalpark Berchtesgarden, Germany. Aquat Insects 27: 125-131.

Thienemann A (1954) Chironomus. Leben, Verbreitung und wirtschaftliche Bedeutung der Chironomiden. Binnengewässer 20: $1-834$. 